\title{
CONSTRUCTIONS MOBILE ROBOT AND WORKING TECHNOLOGY
}

\author{
Adrian Bruja, Marian Dima and Cătălin Frâncu \\ Technical University of Civil Engineering \\ 122-124 Lacul Tei Blv., Bucharest, Romania \\ \{bruja, dima, francu\}@mail.utcb.ro
}

\begin{abstract}
In this paper is presented a mobile robot for the buildings construction, which, endowed with gripping and adequate tools, can carry out operations of handling, masonry or finishing in the construction industries.

The robot has in its componence the following mechanisms:

- mechanism of orientation with 2 DOF's (2 R);

- mechanism of positioning with 3 DOF's (2 TR);

- mechanism of displacement with 1 DOF's (R);

- steering mechanism with 1 DOF (T).

A mechanism of orientation by horizontal locus is added and ensures, before beginning work in a given position, orientation of the robot's platform in horizontal position. The orientation is made using 4 devices to fix with mechanical action, which have also the role to support the robot during work. The orientation is not made in a robotized mode, but in an automated mode, using an inclinometer to measure the slope according to two axes.
\end{abstract}

\section{KEYWORDS}

Mobile Robots, Civil Engineering Flexible Cell

\section{INTRODUCTION}

The mobile robot for construction was designed to complete different technological tasks in construction works like: masonry and finishings, making it the central component of a robotized flexible cell for construction of residential buildings of $1 \ldots 3$ floors.

The mobile robot for construction is represented in figure 1 and is composed of an orientation mechanism with 2 DOF's RR (axes I and II), a positioning mechanism with 3DOF's TTR (axes
III, IV and V) and chassis with mechanisms for moving, steering and wedging.

\section{ORIENTATION MECHANISM}

The orientation mechanism of the mobile robot for construction is composed of a driving mechanism for axis I, fig.1, pos 1, and driving mechanism for axis II, fig. 1 pos 2 .

The driving mechanism of axis $\mathrm{I}$, is presented in figure 2 and is composed of: motor 1 , bracket 2 , planetary reducer with pins 3 , flange 4 , which connects the reducer with output shaft 5 . 


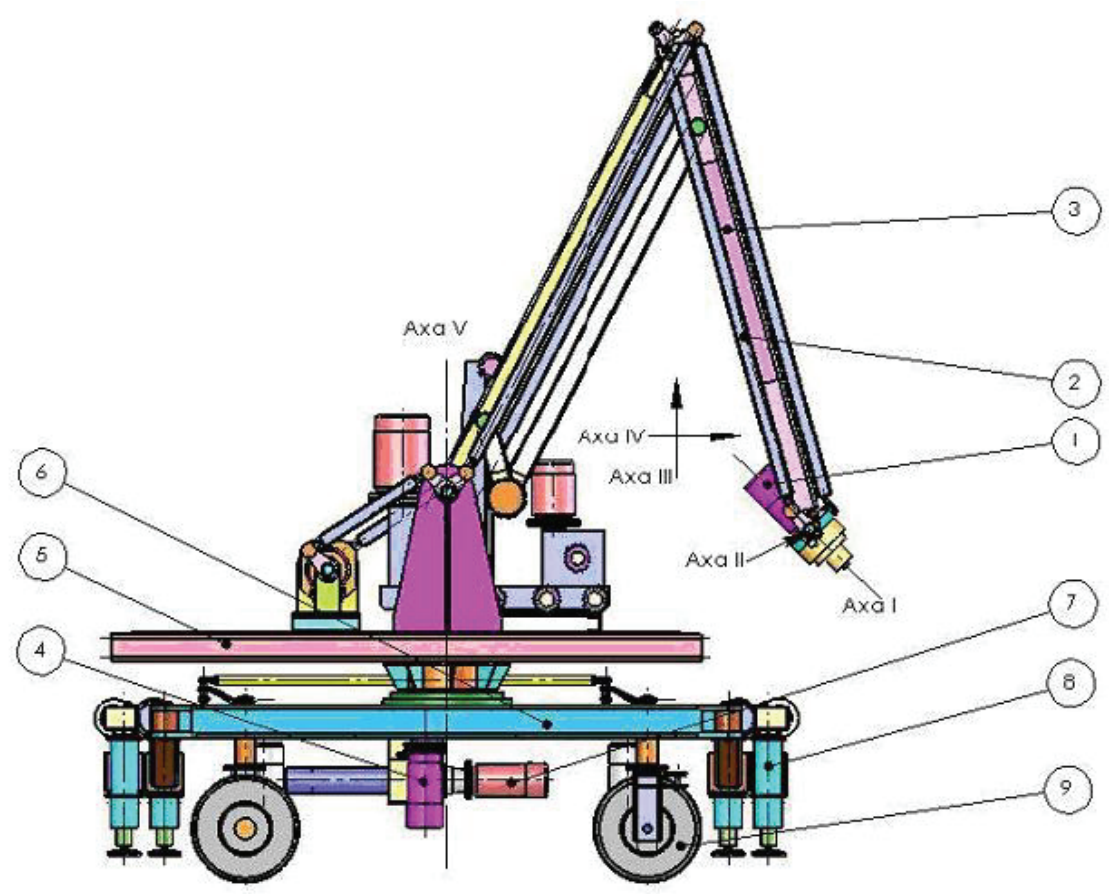

Figure 1 Mobile Robot for Construction

Output shaft 5 is retained by ball bearing 6 . On output shaft 5 is fixed the grasping device which rotates around axis I together with the output shaft. The motor is provided with brake and an encoder.

The driving mechanism of axis II is presented in figure 3 and is composed of two mechanisms with bars placed on one side and the other of the arms of the positioning mechanism and a motion mechanism. The two mechanisms with bars are each composed of three parallelogram mechanisms. Following notations from the figure, the mechanism with bars from the right side of the positioning mechanism is composed of the parallelogram mechanism 3, 4, 5, platform, parallelogram mechanism $6,7,8$, inferior arm of the positioning mechanism and $9,10,11$, superior arm of the positioning mechanism. The mechanism from the left side is identical but the crank is rotated $90^{\circ}$ in vertical plane, relatively to the crank from the right side. By locating the cranks this way, is allowed the continuity of the movement taking each other out from blocking positions.

The motion mechanism is composed of motor 1 and planetary reducer with pins 2 having the output shaft with two exits. The output shaft of the reducer is joined with the two driving cranks of parallelogram mechanisms from left and right. The shaft 12 materializes the axis II and is fixed to the cranks and the bracket of the driving mechanism, axis I, 14. The shaft is supported by ball bearings 13 fixed to the superior arm of the positioning mechanism.

How it works - The output shaft from the reducer rotates the cranks 3 which are move the three parallelogram mechanisms. All the cranks of the parallelogram mechanisms rotate synchronously with the crank 3 (reduction ratio 1:1). The crank 11 rotates around axis II the shaft 12 which rotates relatively to the axis II the bracket and mechanism 14. The motor is provided with brake and an encoder. By stopping the motor, the mechanism 14 is locked in the desired position. Parallelogram mechanisms have the duty to maintain the mechanism 14 in this position independently of the positioning mechanism movements. To both mechanisms, the feed-back is closed to the motor output shaft and this is the reason that the mechanical transmission has to be backlash free. This requirement asked for the planetary reducers with pins. 


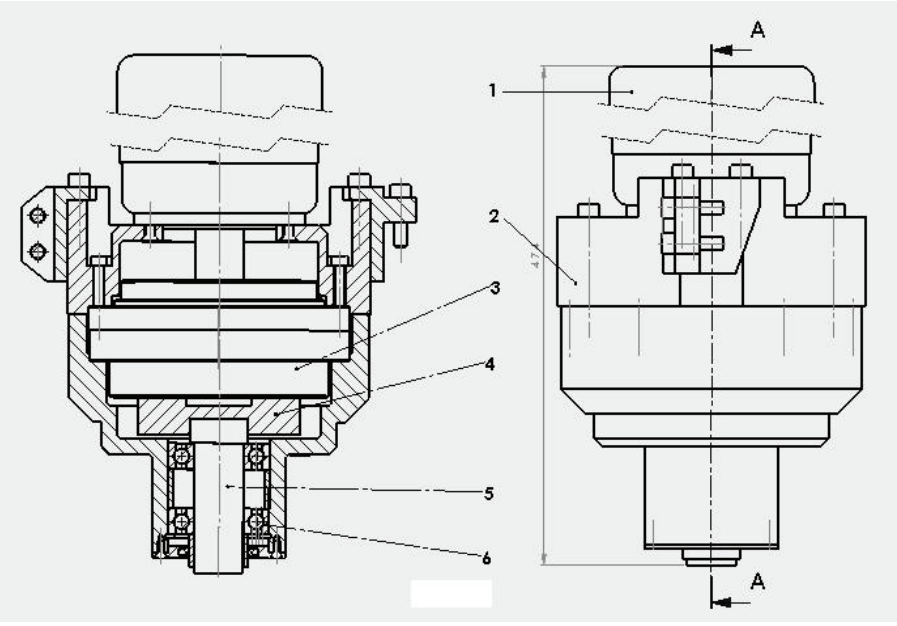

Figure 2 Driving Mechanism of Axis I

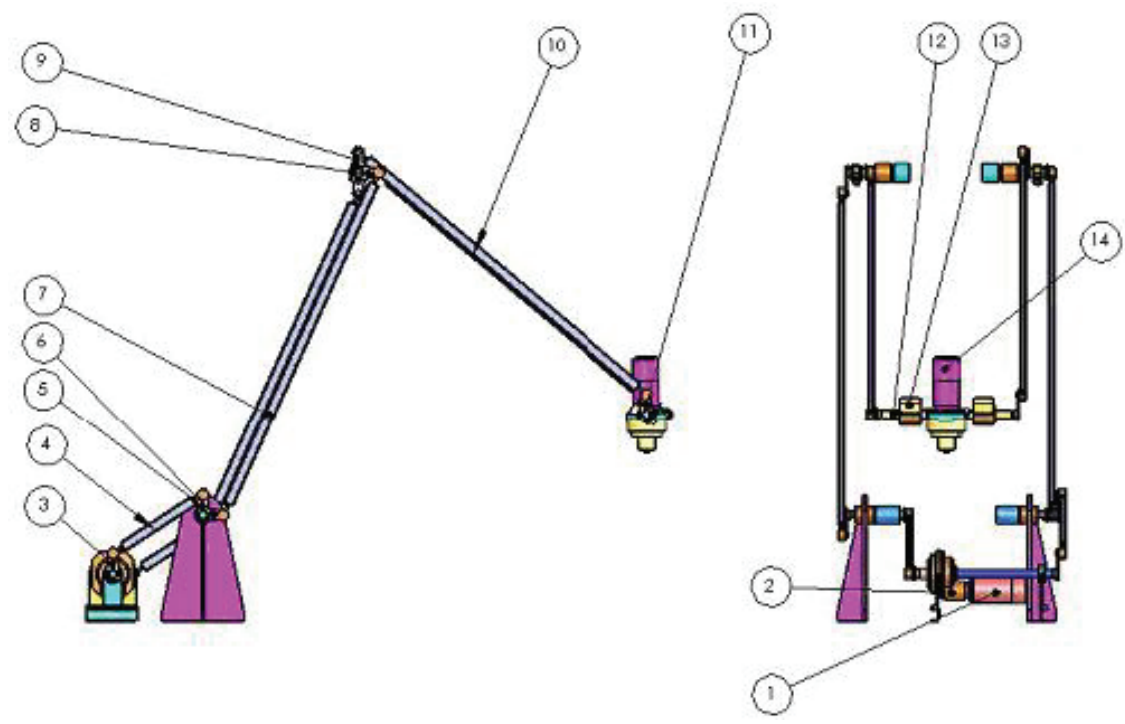

Figure 3 Driving Mechanism of Axis II

\section{POSITIONING MECHANISM}

The purpose of the positioning mechanism (Fig. 1 pos. 3) is to move the orientation mechanism and the grasping device in different points of the workspace. It is composed of (fig. 4), a bar mechanism, which makes the movements by axes III and IV and the rotation mechanism around the axis $\mathrm{V}$.

The bars mechanism is composed of a pantograph mechanism and a mechanism for moving vertically and horizontally the joint $C$, (pos. 5). The pantograph mechanism is composed of the superior arm (pos.1), inferior arm (pos.4) and bars 2 and 3 fixed through a joint in $\mathrm{C}$ and to bar 2 respectively 3 making this way a parallelogram mechanism. The mechanism is attached to the fixed joint $\mathrm{A}$ in platform 6 ant through $\mathrm{C}$ to the motion mechanism 5.

How it works - by moving the joint $\mathrm{C}$ parallel to the axes III or IV is obtained an amplified movement with the characteristic coefficient $\mathrm{K}$ of the mechanism to the joint $G$ of the orientation mechanism by axis III respectively IV. 


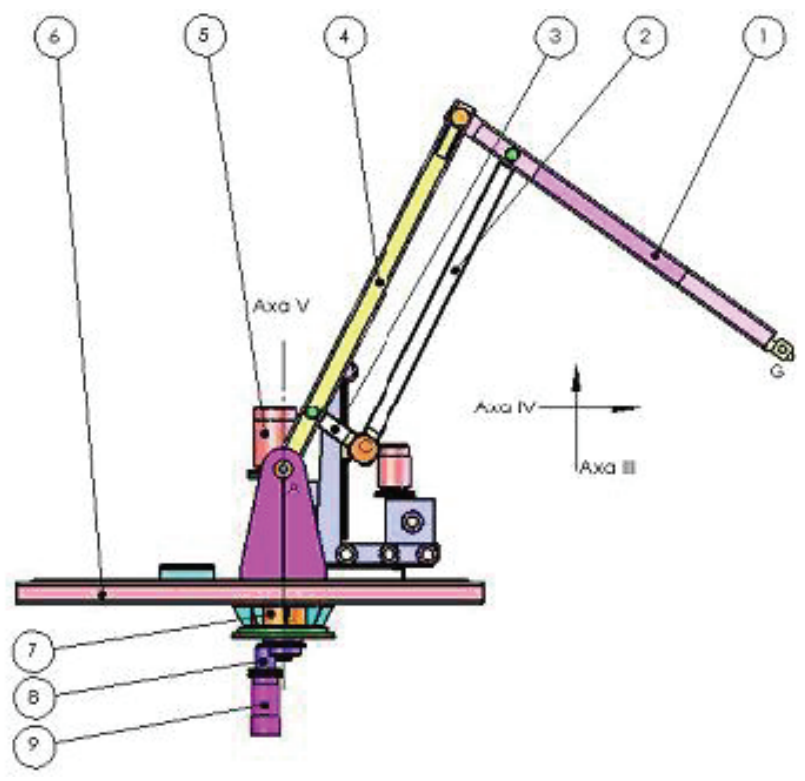

Figure 4 The Positioning Mechanism

By moving simultaneously joint $\mathrm{C}$ by the two axes, curves of second order in the pantograph's mechanism plane. By rotating simultaneously the platform, are obtained spatial trajectories for the joint $\mathrm{G}$ are obtained.

Rotation mechanism relatively to axis $\mathrm{V}$ is composed of motor 9 , planetary reducer with pins 8 and axial ball bearing in case 7 . The motor is provided with brake and an encoder. In this case the feedback is closed at motor shaft and reason to which it was used the planetary reducer with pins (very small backlash, considered negligible).

\section{CHASSIS CONTAINING MECHANISMS FOR MOTION, STEERING AND WEDGING}

\subsection{Chassis and Wedges}

Are represented in figure 5 (closed position of wedges) and figure 6 (opened wedges). The four wedges (pos. 2) are articulated to the chassis corners 1 . Wedge opening is done manually by rotating them at the working site. Wedging is done automatically by the computer by raising or lowering the chassis.

Every wedge is composed of a folding arm 3, case of the wedge 6 , telescopic boom 7 and the shoe 8 . Raising and lowering are done by using the worm gear motors 4 and 5 which drive a screw mechanism.

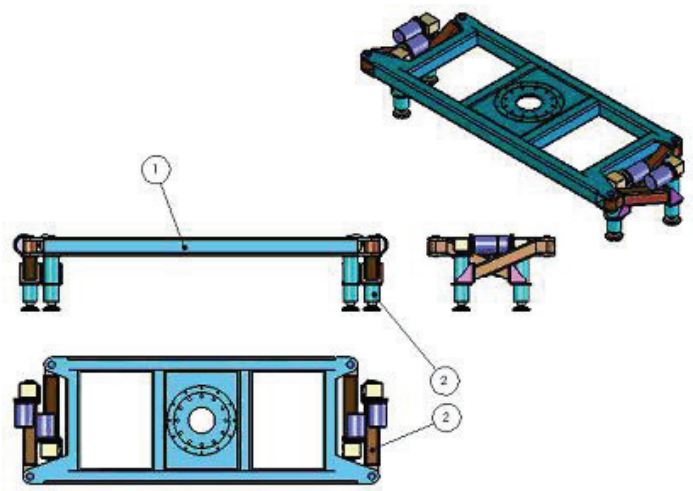

Figure 5 Chassis with Closed Wedges

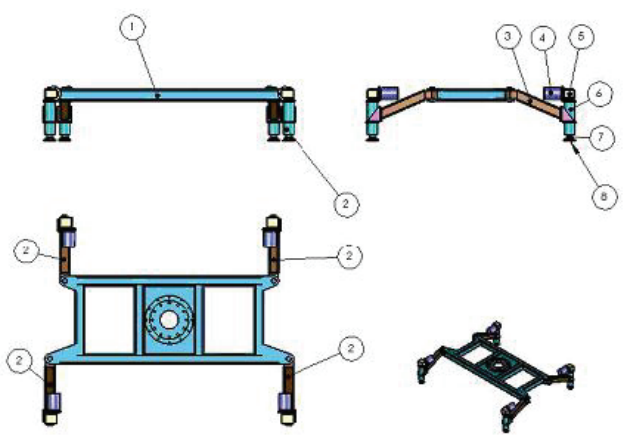

Figure 6 Chassis with Opened Wedges 


\subsection{Steering Mechanism}

This is a parallelogram mechanism and is presented in figure 7 . This mechanism insures the rotation of all the four wheels with an angle of $0 \div 90^{\circ}$ allowing the robot to move on different directions, with zero turn radius.

If the chassis need to rotate around the vertical axis $\mathrm{V}$, in order to be placed for an desired direction, for example parallel to a wall, the wheels are rotated $45^{\circ}$ in horizontal plane and by moving the driving wheels in opposite way a rotation of the chassis in horizontal plane is obtained.

The steering mechanism is composed of the driving mechanism, and the bars mechanism. The driving mechanism is composed of the motor with brake and encoder, the planetary reducer with pins 3 and ball-screw mechanism 4 . The wheels are articulated to the low part of the brackets $\mathrm{F}$ The vertical shafts of the brackets are articulated to the chassis through ball bearings 1 and are fixed to.
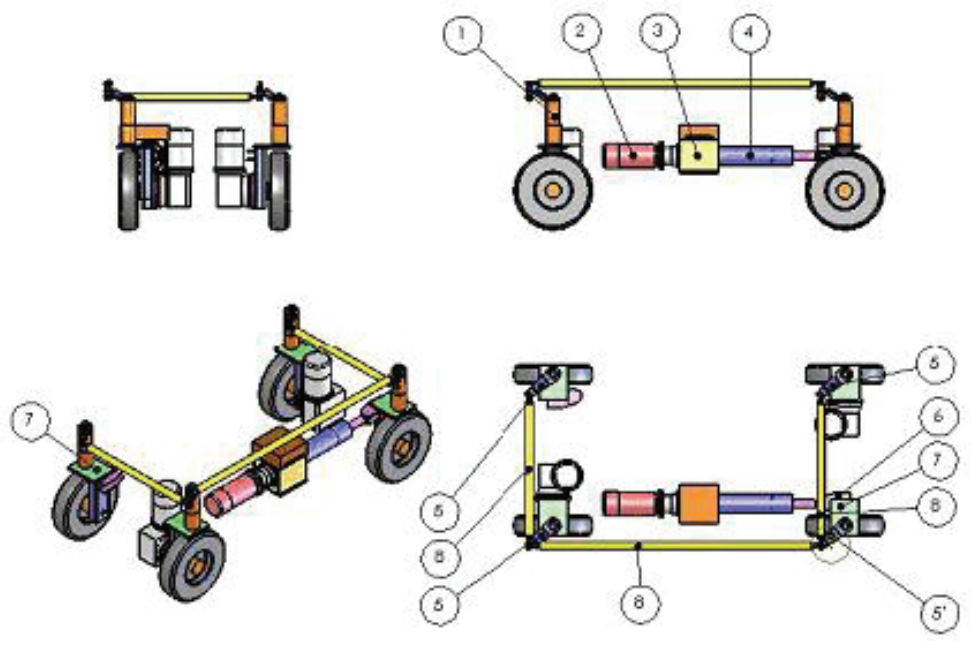

Figure 7 Steering Mechanism
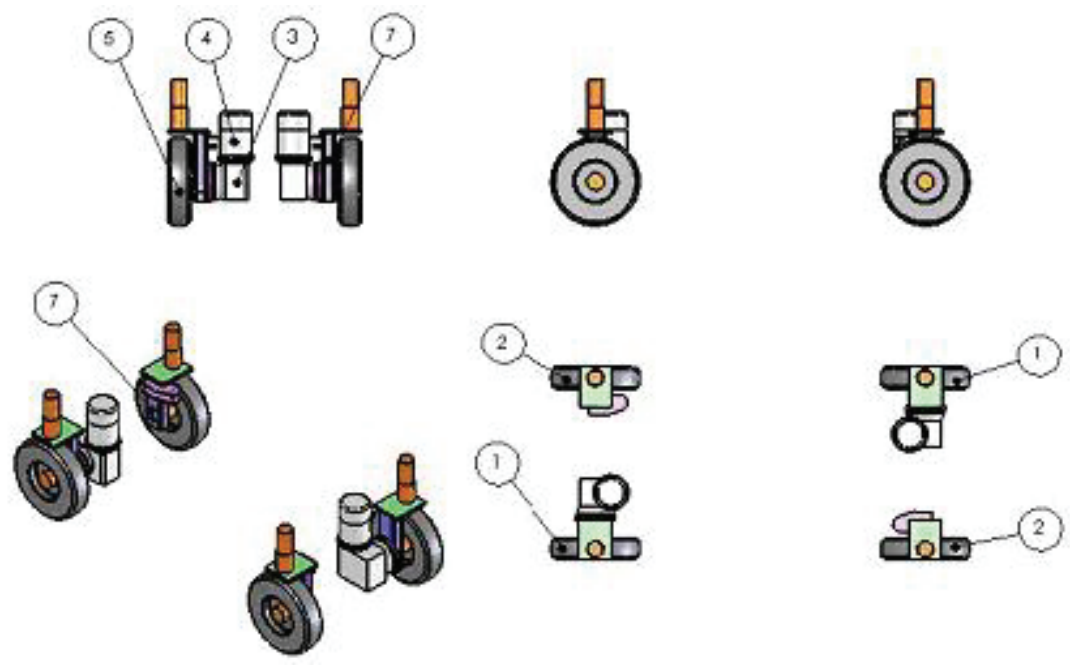

Figure 8 Motion Mechanism 
the cranks 5 of the 3 parallelogram mechanisms (1, 5, 8, 5'). Rotating the crank 5' with the desired angle, the movement is transmitted to the other cranks which rotate with the same angle. The crank $5^{\prime}$ is rotated by the driving mechanism which is articulated to the frame 7 and fixed to the crank.

\subsection{Motion Mechanism}

Motion mechanism is presented in figure 8 . Motion mechanism is composed of 4 wheels articulated to the frames 7 with two driving wheels
1 , and two are free 2. The driving wheel 5 is powered by a worm gear motor 3,4 .

\section{REFERENCES}

[1] Adrian BRUJA, Marian DIMA (2006) Componența şi funcționarea robotului mobil universal pentru construcții. Simpozionul INFOSOC „Cercetări privind Societatea Informațională - rezultate şi perspective", Sibiu, $7-9$ dec. 